\title{
Concomitant Medication Daily Dose
}

National Cancer Institute

\section{Source}

National Cancer Institute. Concomitant Medication Daily Dose. NCI Thesaurus. Code C83025.

The gross amount of concomitant medication that the subject is exposed to each day. 